\title{
Influência da qualidade de luz no crescimento e acúmulo de voláteis de Mentha spicata cultivada in vitro
}

Influence of light quality on growth and volatile accumulation of Mentha spicata grown in vitro

\author{
S. H. B. da Cunha'; S. T. Silva ${ }^{1}$; S. K. V. Bertolucci ${ }^{2}$ A. A. de Carvalho ${ }^{1}$; T. T. \\ Rocha $^{1}$; J. E. B. P. Pinto ${ }^{1 *}$ \\ ${ }^{l}$ Departamento de Agricultura/Laboratório de Cultura de Tecidos Vegetais/Setor de Plantas Medicinais, Universidade \\ Federal de Lavras, 37200-000, Lavras-Minas Gerais, Brasil \\ ${ }^{2}$ Departamento de Agricultura/Laboratório de Fitoquímica e Plantas Medicinais/Setor de Plantas Medicinais, \\ Universidade Federal de Lavras, 37200-000, Lavras-Minas Gerais, Brasil
}

*jeduardo@ufla.br

(Recebido em 31 de julho de 2019; aceito em 04 de setembro de 2019)

\begin{abstract}
Os objetivos deste trabalho foram investigar a influência da qualidade da luz no crescimento e no acúmulo de constituintes voláteis de Mentha spicata cultivada in vitro. Segmentos nodais de plântulas já estabelecidas foram mantidos sob lâmpadas fluorescentes e diodos emissores de luz (LEDs) com as regiões espectrais nas cores verde, amarelo, vermelho, azul e branco, e nas combinações entre vermelho e azul (1:1; 2:2 e 2:1). Após 45 dias, parâmetros de crescimento, área foliar, índices de crescimento, pigmentos fotossintéticos e análise da composição química volátil de folhas por headspace - CG/FID foram avaliados. A combinação 1:2 proporcionou maiores biomassas seca de folhas, raiz e total. As plântulas dos tratamentos verde, amarelo, fluorescente e vermelho apresentaram características de estiolamento. Em relação à composição química volátil, os constituintes majoritários $\alpha$-pineno, sabineno, $\beta$-pineno, mirceno, 1,8-cineol e carvona foram identificados. Plântulas crescidas sob LEDs verde e amarelo resultaram maior acúmulo de carvona. Assim, este estudo contribuiu para o entendimento das alterações causadas pela qualidade de luz no crescimento in vitro e na composição química volátil de hortelã. Conclui-se que a micropropagação de Mentha spicata sob LEDs na combinação entre vermelho e azul 1:2 é o mais favorável para o crescimento e teor de carvona e de 1,8-cineol.

Palavras-chave: metabólitos secundários, micropropagação, qualidade de luz.
\end{abstract}

The objective of this study was to investigate the influence of light quality on the growth and accumulation of volatile constituents of Mentha spicata grown in vitro. Nodal segments of already established plantlets were maintained under fluorescent lamps and light-emitting diodes (LEDs) with spectral regions in green, yellow, red, blue, and white, and in the combinations between red and blue $(1: 1 ; 2: 2$, and 2:1). After 45 days, growth parameters, leaf area, growth index, photosynthetic pigments, and analysis of the volatile chemical composition of leaves by headspace-CG/FID were evaluated. The 1:2 combinations provided larger leaf, root, and total dry weight. Green, yellow, fluorescent, and red plantlets presented characteristics of etiolation. In relation to the volatile chemical composition, the major constituents $\alpha$-pinene, sabinene, $\beta$-pinene, myrcene, 1,8-cineol, and carvone were identified. Plantlets grown under green and yellow LEDs resulted in greater accumulation of carvone. Thus, this study contributed to the understanding of the changes caused by light quality in vitro growth and in the volatile chemical composition of mint. It is concluded that the micropropagation of Mentha spicata under LEDs in the combination of red and blue 1:2 is the most favorable for growth and content of carvone and 1,8-cineol.

Keywords: secondary metabolites, micropropagation, light quality.

\section{INTRODUÇÃO}

Mentha spicata, conhecidas como hortelã ou menta, apresenta relevante importância econômica devido ao mentol, geralmente o constituinte majoritário do seu óleo essencial, com demanda global anual acima de 7000 toneladas [1]. A aplicação das plantas deste gênero como alimentos, medicamentos, especiarias e agentes aromatizantes é bem conhecida, sendo estes usos proporcionados pelo seu óleo essencial [2]. Além do mentol, verifica-se a presença de outros constituintes básicos, como mentona, 1,8-cineol (eucaliptol), mentofurano, limoneno, pulegona e 
carvona. Estes constituintes conferem as espécies de Mentha propriedades farmacológicas como atividade citotóxica, antimicrobiana, antitumoral, antioxidante e analgésica [3].

As mentas são propagadas de maneira vegetativa devido os híbridos do gênero produzirem sementes estéreis. A micropropagação aplicada às plantas medicinais é uma técnica que possibilita o cultivo homogêneo, em larga escala, e manutenção ou manipulação da qualidade fitoquímica do material. Para a obtenção de qualidade fitoquímica, fatores do ambiente de cultivo in vitro devem ser otimizados, como a composição espectral da luz. Em laboratórios de micropropagação, lâmpadas fluorescentes brancas ainda são as mais utilizadas, no entanto, os diodos emissores de luz (LEDs) têm sido aplicados com sucesso [4].

Diversos fatores ambientais influenciam o crescimento, desenvolvimento e metabolismo de plantas, sendo a fonte luminosa uma variável de grande importância. As plantas podem apresentar diferentes respostas aos estímulos de luz, inclusive a diferentes composições espectrais [5]. Consideram-se a luz vermelha e a azul as de maior impacto no crescimento e desenvolvimento das plantas. A qualidade da luz de LEDs influenciou o crescimento e constituintes voláteis de espécies medicinais, como ocorreu em Achillea millefolium [6], Plectranthus amboinicus [7] e Lippia gracilis [8]. Em relação ao crescimento, para verificar o efeito da mudança da composição espectral, o estudo de pigmentos fotossintéticos tem sido realizado, pois fornece um diagnóstico da funcionalidade do aparato fotossintético da planta [9].

Portanto, espécies do gênero Mentha são alimentos funcionais, matéria-prima para a indústria e apresentam diversas propriedades farmacológicas. Levando-se em consideração a necessidade de obtenção de composição química volátil de qualidade, assim como o cultivo por método assexuado, objetivou-se avaliar o crescimento, pigmentos fotossintéticos e composição química volátil por headspace-CG/DIC de hortelã (Mentha spicata) cultivada in vitro sob diferentes qualidades de luz (LEDs).

\section{MATERIAL E MÉTODOS}

\subsection{Estabelecimento e análise de crescimento}

Para o estabelecimento do explante, segmentos apicais e nodais foram retirados de plantas matrizes cultivadas em casa de vegetação com sistema de fertiirrigação. Em seguida, estes explantes passaram por assepsia, onde foram tratados com solução de 50\% de água sanitária (1\% de cloro ativo), durante 20 minutos, sob agitação constante. Posteriormente foram lavados 4 vezes com água destilada autoclavada e inoculados na vertical em tubos de ensaio contendo meio MS [10], com $30 \mathrm{~g} \mathrm{~L}^{-1}$ de sacarose, $6 \mathrm{~g} \mathrm{~L}^{-1}$ de ágar e $\mathrm{pH}$ ajustado para 5,7 $\pm 0,1$. As plântulas obtidas foram mantidas em sala de crescimento com condições controladas, sendo o fotoperíodo de 16 horas de luz, com lâmpadas fluorescentes brancas frias de $42 \mu \mathrm{mol} \mathrm{m}^{-2} \mathrm{~s}^{-1}$, e temperatura de $26 \pm$ $1{ }^{\circ} \mathrm{C}$.

Os explantes utilizados no experimento foram excisados destas plântulas estabelecidas in vitro. Segmentos nodais, de aproximadamente $1 \mathrm{~cm}$, foram inoculados na vertical em tubo de ensaio contendo $12,5 \mathrm{~mL}$ de meio de cultura $\mathrm{MS}$, com $30 \mathrm{~g} \mathrm{~L}^{-1}$ de sacarose, $6 \mathrm{~g} \mathrm{~L}^{-1}$ de ágar e $\mathrm{pH}$ ajustado para 5,7 $\pm 0,1$. Em seguida, foram mantidos sob diodos emissores de luz (LEDs) nas regiões espectrais do verde, amarelo, vermelho, azul e branco, e nas combinações entre vermelho e azul (1:1, 1:2 e 2:1), totalizando 8 tratamentos. Os LEDs utilizados apresentavam intensidade de $42 \mu \mathrm{mol}$ $\mathrm{m}^{-2} \mathrm{~s}^{-1} \mathrm{e}$ como controle foi utilizada lâmpada fluorescente branca fria de $42 \mu \mathrm{mol} \mathrm{m} \mathrm{m}^{-2} \mathrm{~s}^{-1}$. O delineamento experimental utilizado foi o inteiramente casualizado (DIC) com 9 tratamentos, 3 repetições e 6 plântulas por repetição.

Após 45 dias, o comprimento da parte aérea e da maior raiz $(\mathrm{cm})$, número de brotações, folhas e de raízes; matéria seca de folhas, caule, raiz e total (mg), pigmentos fotossintéticos, área foliar, índices de crescimento e análise de folhas por headspace - CG/DIC foram avaliados. Para determinar a matéria seca das plântulas, a secagem foi realizada em estufa de circulação forçada de ar a $37^{\circ} \mathrm{C}$, até atingir o peso constante. 


\subsection{Análises de área foliar e cálculo de índices de crescimento}

A área foliar foi mensurada através do software WinFOLIA ${ }^{\mathrm{TM}}$ pelo scanner EPSON PERFECTION V700 PHOTO. Avaliou-se a área foliar total de cada plântula. A partir dos resultados obtidos, o índice de área foliar (IAF), razão de área foliar (RAF), área foliar específica (AFE), massa foliar específica (MFE) e razão de peso das folhas (RPF) foram avaliados. Utilizouse as fórmulas matemáticas de crescimento descritas [11].

\subsection{Análises dos pigmentos fotossintéticos}

Os pigmentos fotossintéticos analisados foram clorofila $a$, clorofila $b$, clorofila total $\mathrm{e}$ carotenoides. Em uma sala escura sob luz verde $50 \mathrm{mg}$ de folhas frescas foram fragmentadas em tamanho de cerca de $0,5 \mathrm{~cm}$. Estas foram colocadas em tubos falcon revestidos de papel alumínio e contendo $10 \mathrm{~mL}$ de DMSO (Dimetilsulfóxido). Em seguida, esses tubos foram mantidos em estufa a $65^{\circ} \mathrm{C}$ durante 24 horas. Posteriormente, os extratos obtidos foram diluídos em mais $5 \mathrm{~mL}$ de DMSO, seguido de leitura da absorbância (A) à 480 nm, 649 nm, $665 \mathrm{~nm}$ no espectrômetro TECAN INFINITY M200 PRO, operado com o sistema de processamento de dados I-control ${ }^{\circledR}$ versão 3.37. As concentrações de clorofila e carotenoides foram calculadas com base nas seguintes equações: clorofila $a$ (12,47 A665 - 3,62 A649); clorofila $b$ (25,06 A649 - 6,5 A665); clorofila total $(a+b)$; e carotenoides (1000 A480 - 1,29 Ca-53,78 Cb)/220. O resultado foi obtido em miligramas (mg) de pigmento, por gramas (g) de matéria fresca de folha.

\subsection{Análises da composição química volátil por headspace}

Utilizou-se o extrator "headspace" automático CombiPAL Autosampler System (CTC Analytic AG, Switzerland) acoplado ao sistema de cromatografia em fase gasosa Agillent 7890A e detector de ionização em chamas (GC-DIC). As condições operacionais do extrator headspace foram as seguintes: temperatura de incubação da amostra de $110^{\circ} \mathrm{C}$ durante $30 \mathrm{~min}$, temperatura da seringa a $120^{\circ} \mathrm{C}$. O volume de injeção foi de $1000 \mu \mathrm{L}$ da fase de vapor, injetados em modo split na razão 20:1. As amostras constituíram de $70 \mathrm{mg}$ de folhas secas de Mentha spicata, acondicionadas em vials de $20 \mathrm{~mL}$, vedados com septo de silicone /PTFE.

Utilizou-se uma coluna capilar de sílica fundida DB-WAX (30 m de comprimento x 0,25 mm de diâmetro interno x $0,25 \mu \mathrm{m}$ de espessura do filme) (Califòrnia, EUA). O gás hélio foi utilizado como gás de arraste com fluxo de $1,0 \mathrm{~mL} / \mathrm{min}$; as temperaturas do injetor e do detector foram mantidas em 220 e $240^{\circ} \mathrm{C}$, respectivamente. A temperatura inicial do forno foi de $60^{\circ} \mathrm{C}$, mantido por 1 minuto, seguido por uma rampa de temperatura de $3^{\circ} \mathrm{C}$ por min até $240^{\circ} \mathrm{C}$, seguida de uma rampa de $10^{\circ} \mathrm{C}$ por minuto até $250^{\circ} \mathrm{C}$, mantendo-se em condição isotérmica por 1 min. Os constituintes químicos foram identificados por comparação dos seus índices de retenção relativos à coinjeção de uma solução padrão de n-alcanos (C8-C20), Sigma- Aldrich ${ }^{\circledR}$, St Louis, USA). Os índices de retenção foram calculados usando a equação de Van den Dool e Kratz (1963) [12] e para as atribuições foram consultados índices de retenção da literatura [13].

\subsection{Análises estatísticas}

Os dados coletados foram submetidos à análise de variância pelo teste $\mathrm{F}(\mathrm{p}<0,05)$. Após verificada a significância, aplicou-se o teste de média Scott-Knott $(p<0,05)$. O software $R$ foi utilizado para as análises estatísticas. A metodologia deve ser descrita com as informações necessárias para permitir a repetição do estudo por outro pesquisador. 


\section{RESULTADOS E DISCUSSÃO}

\subsection{Análises de crescimento}

$\mathrm{O}$ crescimento in vitro de plântulas de Mentha spicata foi significativamente afetado pela qualidade da luz (Figura 1). Observou-se estiolamento das plântulas com cultivo sob lâmpada fluorescente branca e sob LED vermelho, verde e amarelo. Possivelmente, plantas expostas sob luz vermelha aumentaram a síntese de giberelina (GA) e, consequentemente, alongaram o caule. Em Arabidopsis e alface (Lactuca sativa), a expressão da GA AtGA3ox2 3-oxidases (GA4H) e genes Ls3ox1 foi induzida por exposição das sementes a luz vermelha [14]. Assim, a luz vermelha parece promover a síntese de GA1 induzindo a expressão de GA 3-oxidase via ação do fitocromo.
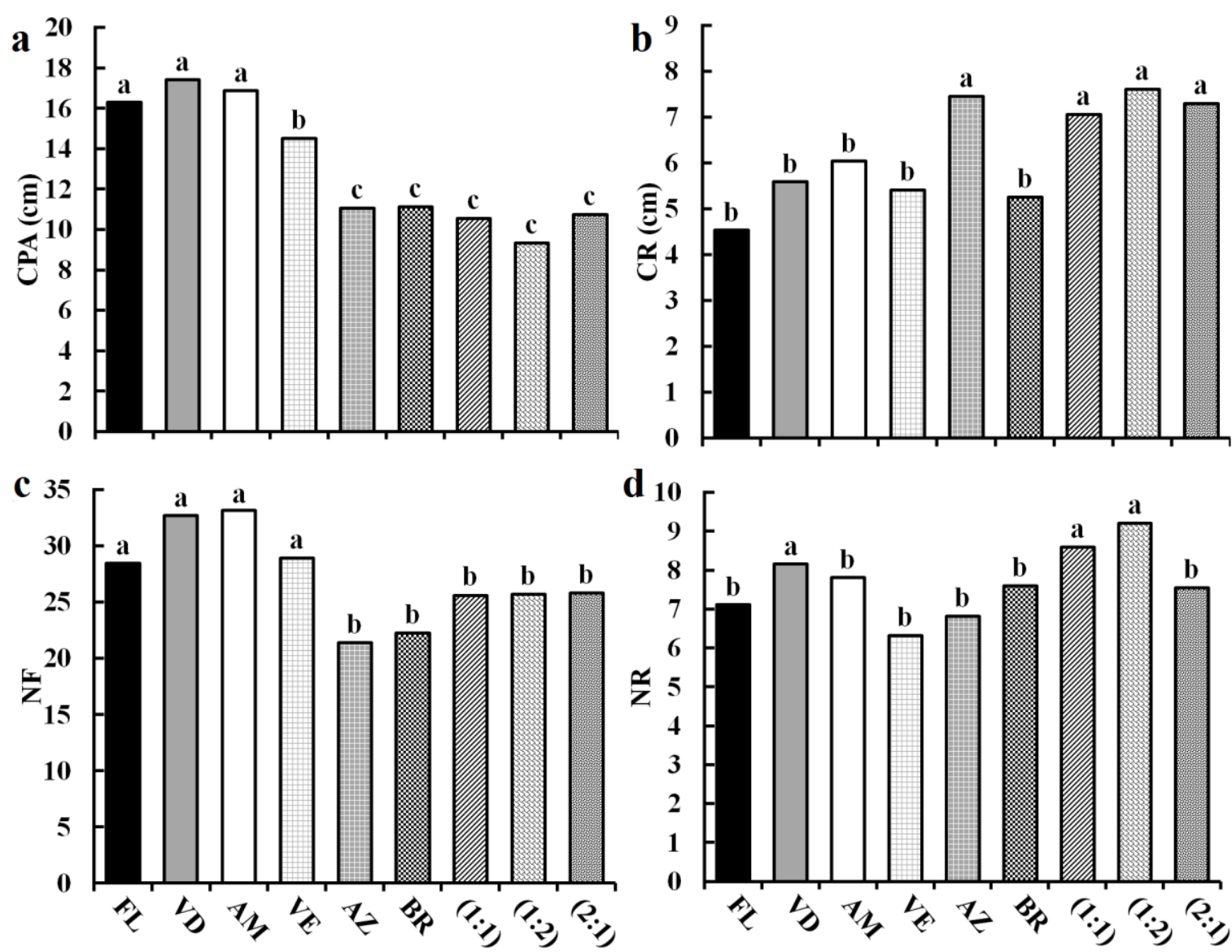

Figura 1 - Aspecto de Mentha spicata cultivada in vitro, após 45 dias, sob diferentes qualidades de luz: a) comprimento da parte aérea (CPA); b) comprimento da raiz (CR); c) número de folhas (NF); d) número

de raizes (NR). FL-fluorescente, VD-verde, AM- amarelo, VE-vermelho, AZ-azul, BR-branco, e combinações entre vermelho e azul (1:1, 1:2, 2:1). Médias seguidas das mesmas letras não diferem entre si pelo Teste de Scott Knott $(p<0,05)$.

As plântulas cultivadas sob luzes fluorescente, verde e amarelo apresentaram maiores comprimento da parte aérea e número de folhas (Figuras 2a-d), e menores biomassas secas totais (Figura 3). Esse fato pode ter ocorrido devido aos comprimentos de onda verde e amarelo serem refletidos ou transmitidos, sendo assim, pouco importantes no processo fotossintético. 

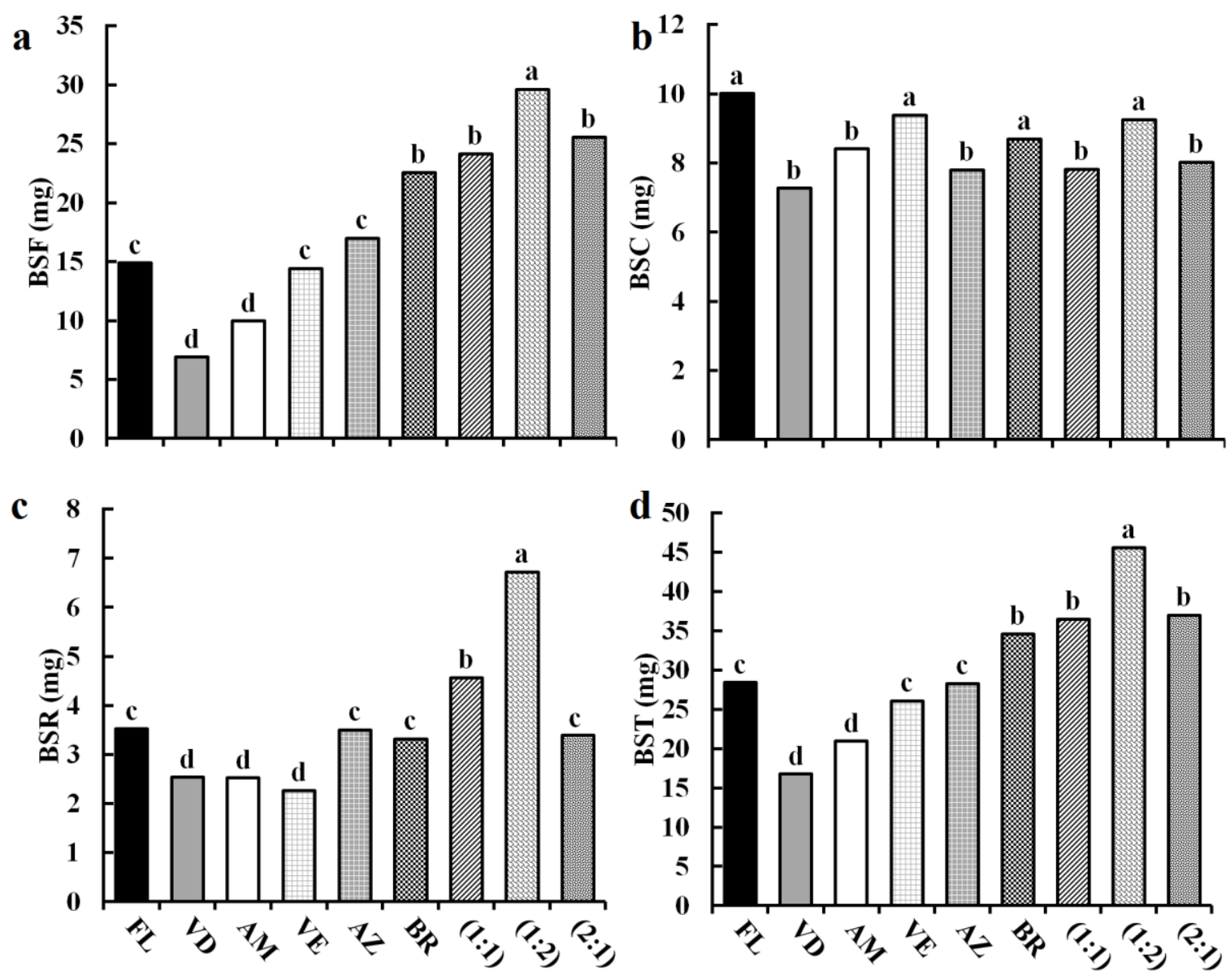

Figura 2- Variáveis de crescimento em Mentha spicata analisadas após 45 dias sob cultivo in vitro em diferentes qualidades de luz. a) biomassa seca de folha (BSF); b) biomassa seca do caule (BSC); c) biomassa seca de raiz (BSR); d) biomassa seca de total (BST). FL-fluorescente, VD-verde, AM-amarelo, VE-vermelho, AZ-azul, BR-branco, e combinações entre vermelho e azul (1:1, 1:2, 2:1). Médias seguidas das mesmas letras não diferem entre si pelo Teste de Scott Knott $(p<0,05)$.

Estudos com Arabidopsis relataram que a luz verde causa efeitos semelhantes quando as plantas estão sombreadas, ou seja, levam ao estiolamento; e causam diferenças na arquitetura da planta como alongamento de pecíolos, reorientação das folhas e redução da área foliar [15]. Em adição, na germinação de sementes, o crescimento do hipocótilo é orientado pela presença de luz. Esse crescimento é uma resposta ativa que ajusta a expansão do caule na fase jovem e complementa os efeitos de sistemas que retardam o crescimento [15]. Muneer et al. (2014) [16] avaliaram o crescimento de plantas de alface (Lactuca sativa L.) cultivadas sob diferentes qualidades de luz, e constataram que o LED verde foi o que proporcionou menor incremento na biomassa. Segundo esses autores, as cores laranja, amarelo e verde (500-600 nm) são utilizadas com menor frequência em estudos científicos e, geralmente, são os tratamentos controles e não as fontes principais de luz. 


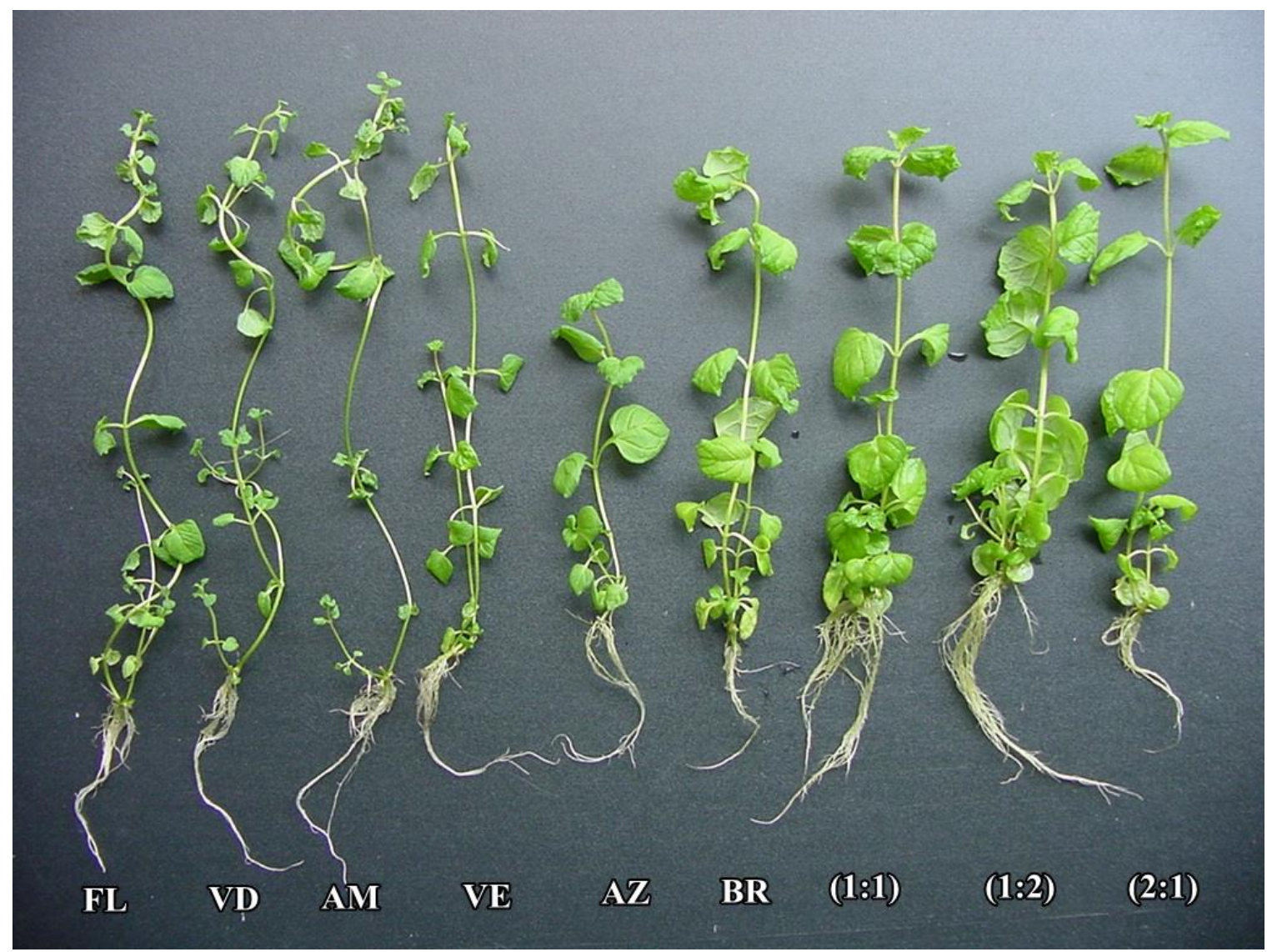

Figura 3- Aspecto de Mentha spicata cultivada in vitro, após 45 dias, sob diferentes qualidades de luz: FL-fluorescente, VD-verde, AM-amarelo, VE-vermelho, AZ-azul, BR-branco, e combinações entre vermelho e azul $(1: 1,1: 2,2: 1)$. Fonte: Os autores.

Quanto ao número de folhas, as médias de plântulas sob a luz vermelha foram estatisticamente iguais às mantidas sob lâmpada fluorescente e aos LEDs verde e amarelo, sendo as maiores médias observadas (Figura 2). As combinações 1:2 e 1:1 proporcionaram maiores resultados em relação ao número de raízes. Já para o comprimento das raízes, as maiores médias foram observadas nas combinações 1:2, 2:1 e 1:1 e azul monocromático (Figura 2-b e d). Mengxi et al. (2011) [17] reportaram que a combinação de luz azul e vermelho promoveram diferenças na morfologia de raízes de Oncidium in vitro, e a medida que havia um aumento na incidência de luz azul resultava em um maior comprimento de raiz.

O número médio de 2 brotos por plântula foi obtido para $M$. spicata, não apresentando diferenças significativas entre os tratamentos. O tratamento com luz azul resultou em menor biomassa seca total que as combinações de vermelho e azul (Figuras 3-d). A possível causa deste resultado é a maior excitação causada pela luz azul. A energia pode ser utilizada, dissipada na forma de calor ou ainda provocar danos no aparato fotossintético como formação de radicais livres. Noguchi e Amaki (2016) [18] avaliaram o crescimento de Plectranthus amboinicus e constataram que plantas cultivadas sob luz azul eram mais compactas, ou seja, de menor tamanho, quando comparadas àquelas cultivadas sob luz vermelha e verde.

De maneira geral, o LED branco (BR) e as combinações 1:1, 1:2 e 2:1 favoreceram o crescimento das plântulas, proporcionando assim, os maiores valores de biomassa seca de folhas e total (Figura 3a e 3d). Destaca-se ainda que a combinação 1:2 resultou em plântulas com maior biomassa seca de raiz, folhas e total (Figuras 3a, 3c e 3d). A combinação 1:2 proporcionou o dobro do valor obtido de BSR em relação à lâmpada fluorescente (FL) (Figuras 3c). As combinações de vermelho e azul são eficientes por proporcionarem melhor excitação dos fotorreceptores, dentre eles fitocromos, criptocromos e fototropinas, causando uma maior atividade fotossintética [19]. Resultados similares foram encontrados com $M$. piperita, $M$. spicata e $M$. longifolia cultivadas em câmara de crescimento [20]. Os autores observaram que para as três mentas, os monocromáticos vermelho e 
azul foram insuficientes para o bom crescimento das plantas, porém as combinações destes espectros (vermelho 70: azul 30\%) resultaram em maiores valores.

Acredita-se que o LED proporcione resultados mais satisfatórios que a lâmpada fluorescente por emitir um comprimento de onda mais específico. Esses efeitos foram observados para M. spicata. A luz branca é uma combinação de baixas intensidades de luzes vermelhas e azuis, e outros comprimentos de onda de luz de baixa eficiência. Isso pode diminuir a taxa de crescimento de plantas iluminadas por luz branca comparada com luzes LED vermelho-azul, como ocorreu para M. spicata (Figura 3). Resultados similares também foram encontrados no trabalho de Li et al. (2013) [21] que cultivaram in vitro Brassica napus L. e verificaram que maior proporção de luz azul (3:1) resultou em maiores resultados quanto à biomassa seca total das plântulas.

Houve diferenças significativas para área foliar total (AFT), razão de área foliar (RAF), área foliar específica (AFE), razão de peso das folhas (RPF) e massa foliar específica (MFE) quando as plântulas de Mentha spicata foram cultivadas sob diferentes regiões espectrais (Tabela 1). Os maiores resultados de área foliar total foram encontrados nos tratamentos com LED branco e na combinação 1:2. Possivelmente, isso ocorreu devido à maior proporção de luz azul, que é absorvida por criptocromos e fototropinas. As fototropinas estão relacionadas à expansão foliar [22]. Pesquisas reportam que diferentes qualidades luminosas podem apresentar efeitos de fotoinibição [23].

Tabela 1- Área foliar total (AFT) e índices para análise de crescimento de plântulas de Mentha spicata cultivadas in vitro sob diferentes qualidades de luz, aos 45 dias. Razão de área foliar $(R A F)$, área foliar específica (AFE), massa foliar específica (MFE) e razão de peso das folhas (RPF).

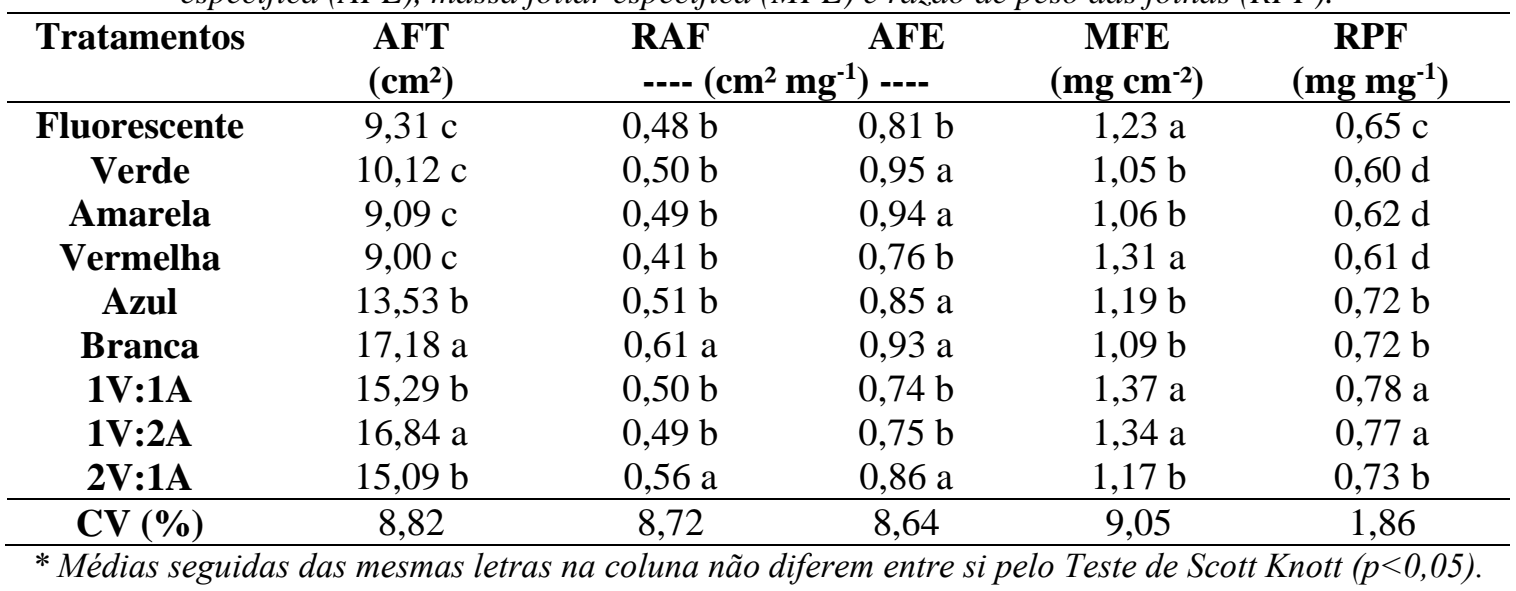

A RAF é uma variável que expressa área foliar útil para a fotossíntese, sendo expressa pela razão entre a área foliar que intercepta a energia luminosa e absorve $\mathrm{CO}_{2}$, e a massa seca total da planta [11]. O LED branco e a combinação 2:1 resultaram nos maiores valores de área foliar e acúmulo de matéria seca (Tabela 1). A AFE representa a razão entre área foliar e biomassa seca da folha, é um fator de importância fisiológica, pois descreve a destinação da biomassa da folha por unidade de área. A maior AFE foi obtida nos tratamentos com luz verde e amarela. Plantas submetidas a esses tratamentos apresentaram sintomas semelhantes às plantas cultivadas em condições de sombreamento (estiolamento). As plantas sombreadas tendem apresentar maior AFE em função das alterações anatômicas que ocorrem em busca de aumentar a captação luminosa e a eficiência fotossintética [24].

A MFE representa a razão entre biomassa seca da folha e área foliar, e está relacionado à espessura das folhas. Os maiores MFE foram encontrados nos tratamentos 1:1 e 1:2. A MFE mais elevada é favorável, pois reduz perda de água e reduz o auto-sombreamento dos cloroplastos [25]. A RPF expressa à fração de matéria seca que não é alocada das folhas para o restante da planta [5]. Plantas jovens tendem a apresentar maiores valores de RPF, pois as partes da planta que ainda surgirão, vão crescer a partir do material transportado das folhas. É uma variável importante para espécies que o interesse econômico concentra-se nas folhas [26]. Neste trabalho com Mentha sp., os melhores valores de RPF foram encontrados nas plântulas cultivadas sob as combinações 1:1 e 1:2, o que pode ser explicado pelo maior acúmulo de biomassa seca de folhas deste tratamento. 


\subsection{Análises dos pigmentos fotossintéticos}

Em relação aos pigmentos fotossintéticos, foi possível observar que as diferentes qualidades de luz afetaram a concentração de clorofila $b$ e total nas plântulas de Mentha sp. Por outro lado, a clorofila $a$ e carotenoides não apesentaram diferenças significativas (Tabela 2). A lâmpada fluorescente foi o tratamento que induziu maiores concentrações em valores absolutos de clorofilas ( $a, b$ e total). Este resultado pode ser explicado pelas lâmpadas fluorescentes serem compostas principalmente pelo espectro do azul, que é eficiente no processo fotossintético, atenuado pela presença de outros comprimentos de onda [27]. Os pigmentos fotossintéticos são capazes de absorver a luz de maneira mais eficaz nos comprimentos de onda do azul e do vermelho [28]. A exemplo, Borowski et al. (2015) [29] relatam em sua pesquisa com plantas de Lactuca sativa L., que a proporção de azul e vermelho aumentou a concentração de clorofilas $a$ e $b$, e quanto aos carotenoides, as plantas cultivadas sob lâmpada fluorescente tiveram resultados similares àquelas cultivadas sob combinação dos LEDs azul e vermelho.

Tabela 2 - Pigmentos fotossintéticos de Mentha spicata cultivada in vitro sobre diferentes qualidades de

\begin{tabular}{ccccc}
\hline Tratamentos & Clorofila $\boldsymbol{a}$ & $\begin{array}{c}\text { Cluz. } \\
\left(\mathbf{m g ~}^{-1} \mathbf{d e} \text { massa }\right.\end{array}$ & $\begin{array}{c}\text { Carotenoides } \\
\text { fresca) }\end{array}$ & Clorofila total \\
\hline Fluorescente & $0,4662 \mathrm{a}$ & $0,5271 \mathrm{a}$ & $0,1340 \mathrm{a}$ & $0,9933 \mathrm{a}$ \\
Verde & $0,3291 \mathrm{a}$ & $0,3474 \mathrm{~b}$ & $0,1196 \mathrm{a}$ & $0,6765 \mathrm{c}$ \\
Amarela & $0,4115 \mathrm{a}$ & $0,3946 \mathrm{~b}$ & $0,1200 \mathrm{a}$ & $0,8061 \mathrm{c}$ \\
Vermelha & $0,3279 \mathrm{a}$ & $0,3882 \mathrm{~b}$ & $0,1395 \mathrm{a}$ & $0,7161 \mathrm{c}$ \\
Azul & $0,3688 \mathrm{a}$ & $0,3955 \mathrm{~b}$ & $0,1230 \mathrm{a}$ & $0,7644 \mathrm{c}$ \\
Branca & $0,3743 \mathrm{a}$ & $0,3471 \mathrm{~b}$ & $0,1077 \mathrm{a}$ & $0,7215 \mathrm{c}$ \\
1V:1A & $0,3905 \mathrm{a}$ & $0,4567 \mathrm{a}$ & $0,1145 \mathrm{a}$ & $0,8471 \mathrm{~b}$ \\
$\mathbf{1 V}: \mathbf{2 A}$ & $0,3452 \mathrm{a}$ & $0,4035 \mathrm{~b}$ & $0,1359 \mathrm{a}$ & $0,7486 \mathrm{c}$ \\
$\mathbf{2 V}: \mathbf{1 A}$ & $0,3382 \mathrm{a}$ & $0,3810 \mathrm{~b}$ & $0,1194 \mathrm{a}$ & $0,7192 \mathrm{c}$ \\
\hline CV (\%) & 12,61 & 11,04 & 13,45 & 8,27 \\
\hline * Médias seguidas das mesmas letras na coluna não diferem entre si pelo Teste de Scott Knott $(p<0,05)$.
\end{tabular}

\subsection{Análises da composição química volátil por headspace}

A análise da fração volátil por headspace-CG-DIC de Mentha spicata cultivada sob diferentes qualidades de luz apresentou um perfil cromatográfico complexo para amostras de folhas da espécie. Foram detectados 31 picos, sendo que seis constituintes caracterizaram entre 91,02 a $94,75 \%$ da composição química total. Destes, 5,41 a 7,57\% caracterizaram-se por monoterpenos hidrocarbonetos ( $\alpha$-pineno, sabineno, $\beta$-pineno e mirceno) e 84,64 a $87,8 \%$ por monoterpenos oxigenados (1,8-cineol e carvona). Sendo estes últimos, os constituintes majoritários, com teor variando de 44,09 a 54,89 para carvona e 30,91 a 42,24\% para 1,8-cineol (Tabela 3). 
Tabela 3- Composição química de Mentha sp. cultivada in vitro sob diferentes qualidades de luz: FLfluorescente, VD-verde, AM-amarelo, VE-vermelho, AZ-azul, BR-branco, e cominações entre vermelho e azul $(1: 1,1: 2,2: 1)$.

\section{Tratamentos}

\begin{tabular}{cccccccccc}
$\begin{array}{c}\text { Constituinte } \\
\text { s }\end{array}$ & $\mathbf{F L}$ & $\mathbf{V D}$ & $\mathbf{A M}$ & $\mathbf{V E}$ & $\mathbf{A Z}$ & $\mathbf{B R}$ & $\mathbf{1 : 1}$ & $\mathbf{1 : 2}$ & $\mathbf{2 : 1}$ \\
\hline a-pineno & $2,59 \mathrm{a}$ & $2,57 \mathrm{a}$ & $2,54 \mathrm{a}$ & $2,54 \mathrm{a}$ & $2,44 \mathrm{~b}$ & $2,59 \mathrm{a}$ & $2,31 \mathrm{~b}$ & $2,38 \mathrm{~b}$ & $2,43 \mathrm{~b}$ \\
Sabineno & $1,97 \mathrm{a}$ & $2,28 \mathrm{a}$ & $2,18 \mathrm{a}$ & $1,96 \mathrm{a}$ & $1,19 \mathrm{a}$ & $1,89 \mathrm{a}$ & $1,81 \mathrm{a}$ & $1,96 \mathrm{a}$ & $2,31 \mathrm{a}$ \\
$\boldsymbol{\beta}$-pineno & $1,15 \mathrm{a}$ & $0,99 \mathrm{a}$ & $1,15 \mathrm{a}$ & $1,09 \mathrm{a}$ & $1,16 \mathrm{a}$ & $0,76 \mathrm{a}$ & $0,77 \mathrm{a}$ & $0,88 \mathrm{a}$ & $1,18 \mathrm{a}$ \\
Mirceno & $1,24 \mathrm{a}$ & $0,69 \mathrm{a}$ & $1,33 \mathrm{a}$ & $0,96 \mathrm{a}$ & $1,53 \mathrm{a}$ & $1,14 \mathrm{a}$ & $0,52 \mathrm{a}$ & $1,32 \mathrm{a}$ & $1,65 \mathrm{a}$ \\
& 42,24 & 30,91 & 31,37 & 33,36 & 34,32 & 35,88 & 37,37 & 35,72 & 40,97 \\
$\mathbf{1 , 8}-\mathbf{c i n e o l}$ & $\mathrm{a}$ & $\mathrm{b}$ & $\mathrm{b}$ & $\mathrm{b}$ & $\mathrm{b}$ & $\mathrm{b}$ & $\mathrm{a}$ & $\mathrm{b}$ & $\mathrm{a}$ \\
& 45,56 & 54,89 & 54,42 & 51,43 & 50,44 & 48,76 & 48,69 & 49,23 & 44,09 \\
Carvona & $\mathrm{c}$ & $\mathrm{a}$ & $\mathrm{a}$ & $\mathrm{b}$ & $\mathrm{b}$ & $\mathrm{b}$ & $\mathrm{b}$ & $\mathrm{b}$ & $\mathrm{c}$ \\
\hline Total & 94,75 & 92,33 & 92,99 & 91,34 & 91,08 & 91,02 & 91,47 & 91,49 & 92,63 \\
\hline * Médias seguidas das mesmas letras na linha, não diferem entre si pelo Teste de Scott-Knott $(p<0,05)$
\end{tabular}

Óleos essenciais ricos em carvona foram detectados como sendo majoritários também em $M$. longifolia, M. suaveolens e $M$. spicata [30]. Os LEDs verde e amarelo foram os que proporcionaram a maior quantidade de carvona (54,89 e 54,42\%; respectivamente) (Tabela 3 ). Esses tratamentos também foram os que apresentaram menor teor de 1,8-cineol (30,91 e 31,37\%; respectivamente). Esta relação inversa ocorreu possivelmente porque o 1,8-cineol é precursor da carvona na rota biossintética dos terpenos. Peer e Langenheim (1998) [31] quantificaram carvona e limoneno em sementes de Carum cawi L. e relacionou-os com a morfologia da planta. De acordo com esses pesquisadores, quando a planta não apresenta restrições em sua morfologia, ou seja, quando crescem mais, são capazes de acumular maiores teores de carvona. Esse resultado possivelmente explica o motivo de no presente trabalho as plântulas dos tratamentos verde e amarelo apresentarem maiores teores de carvona, que ocorreu em função do estiolamento, com isso as plântulas cresceram mais e tiveram maior comprimento de parte aérea e número de folhas, logo possuíam mais tricomas que é onde esses compostos são sintetizados.

Existem vários fatores capazes de influenciar o acúmulo de monoterpenos nas folhas vegetais, dentre eles é possível citar a luz. O fitocromo é o fotorreceptor da luz vermelha que possibilita resposta das plantas às condições ambientais. Estudos sugerem que a resposta fitocromática clássica, induz um efeito negativo à luz vermelha em função da baixa fotorreversibilidade. Porém no estudo da carvona, o aumento do efeito fotorreversível na luz vermelha desta tem indicado que o fitocromo tem influência no seu acúmulo [31]. Esses resultados contribuem para o presente trabalho, uma vez que os tratamentos que obtiveram incidência da luz vermelha apresentaram bons resultados quanto à presença da carvona. Em relação aos monoterpenos hidrocarbonetos (sabineno, $\beta$-pineno e mirceno) não foram encontrados nenhuma diferença estatística.

\section{CONCLUSÃO}

LEDs com combinação entre vermelho e azul 1:2 favorecem o crescimento in vitro de Mentha spicata, proporcionando assim, maiores acúmulos de biomassa seca, área foliar total, massa foliar especifica e razão de peso das folhas. O crescimento favorável e adaptação das plântulas na combinação 1:2 são confirmados pela sua composição de pigmentos fotossintéticos. Maior concentração de carvona é encontrada sob LEDs verde e amarelo.

\section{AGRADECIMENTOS}

À Coordenação de Aperfeiçoamento de Pessoal de Nível Superior (Capes - código de financiamento 001), ao Conselho Nacional de Desenvolvimento Científico e Tecnológico (CNPq) 
e Fundação de Pesquisa de Minas Gerais (FAPEMIG), pelo auxílio financeiro e concessão de bolsas de estudo e produtividade.

\section{REFERÊNCIAS BIBLIOGRÁFICAS}

1. Deschamps C, Monteiro R, Machado M, Bizzo H, Biasi L. Biomass production, essential oil yield, and composition of Mentha x piperita L. according to nitrogen sources and doses. Rev Bras Plantas Med. 2012;14(1):12-7. doi:10.1590/S1516-05722012000100003

2. Bahadori MB, Zengin G, Bahadori S, Dinparast L, Movahhedin N. Phenolic composition and functional properties of wild mint (Mentha longifolia var. calliantha (Stapf) Briq.). Int J Food Prop. 2018 Jan;21(1):183-93. doi:10.1080/10942912.2018.1440238

3. Sevindik M. Pharmacological Properties of Mentha species. J Tradit Med Clin Natur. 2018 Jan;7(1):259. doi: $10.4172 / 2573-4555.1000259$

4. Kwon A-R, Oh M-M, Paek K-Y, Park S-Y. The effect of light quality on growth and endopolyploidy occurrence of in vitro-grown Phalaenopsis 'Spring Dancer'. Hortic Environ Biotechnol. 2018 Apr;59(2):179-88. doi:10.1007/s13580-018-0018-y

5. Costa AG, Chagas JH, Bertolucci SKV, Pinto JEB. Níveis de sombreamento e tipos de malha no crescimento e produção de óleo essencial de hortelã-pimenta. Hortic Bras. 2014 Abr-Jun;32(2). doi: 10.1590/S0102-05362014000200013

6. Alvarenga ICA, Pacheco FV, Silva ST, Bertolucci SKV, Pinto JEBP. In vitro culture of Achillea millefolium L.: quality and intensity of light on growth and production of volatiles. Plant Cell Tissue Organ Cult. 2015 Aug;122(2):299-308. doi:10.1007/s11240-015-0766-7

7. Silva ST, Bertolucci SKV, da Cunha SHB, Lazzarini LES, Tavares MC, Pinto JEBP. Effect of light and natural ventilation systems on the growth parameters and carvacrol content in the in vitro cultures of Plectranthus amboinicus (Lour.) Spreng. Plant Cell Tissue Organ Cult. 2017 Jun;129(3):501-10. doi:10.1007/s11240-017-1195-6

8. Lazzarini LES, Bertolucci SKV, Pacheco FV, dos Santos J, Silva ST, de Carvalho AA, et al. Quality and intensity of light affect Lippia gracilis Schauer plant growth and volatile compounds in vitro. Plant Cell Tissue Organ Cult. 2018 Dec;135(3):367-79. doi:10.1007/s11240-018-1470-1

9. Esteban R, Barrutia O, Artetxe U, Fernández-Marín B, Hernández A, García-Plazaola JI. Internal and external factors affecting photosynthetic pigment composition in plants: a meta-analytical approach. New Phytol. 2015 Apr;206(1):268-80. doi:10.1111/nph.13186

10. Murashige T, Skoog F. A revised medium for rapid growth and bio assays with tobacco tissue cultures. Physiol Plant. 1962 Jul;15(3):473-97. doi:10.1111/j.1399-3054.1962.tb08052.x

11. Benincasa M. Análise de crescimento de plantas: noções básicas, Jaboticabal, 42 p. 2003.

12. Van den Dool H, Kratz PD. A generalization of the retention index system including linear temperature programmed gas-liquid partition chromatography. J Chromatogr A. 1963;11:463-71. doi:10.1016/S0021-9673(01)80947-X

13. Adams RP. Identification of essential oil components by gas chromatography/mass spectrometry. 5 online ed: Texensis Publishing; 2017.

14. Bou-Torrent J, Martínez-García JF, García-Martínez JL, Prat S. Gibberellin A1 metabolism contributes to the control of photoperiod-mediated tuberization in potato. PLoS One. 2011 Sept;6(9):e24458. doi:10.1371/journal.pone. 0024458

15. Zhang T, Folta KM. Green light signaling and adaptive response. Plant Signal Behav. 2012 Jan;7(1):758. doi:10.4161/psb.7.1.18635

16. Muneer S, Kim EJ, Park JS, Lee JH. Influence of green, red and blue light emitting diodes on multiprotein complex proteins and photosynthetic activity under different light intensities in lettuce leaves (Lactuca sativa L.). Int J Mol Sci. 2014 Mar;15(3):4657-70. doi:10.3390/ijms15034657

17. Mengxi L, Zhigang X, Yang Y, Yijie F. Effects of different spectral lights on Oncidium PLBs induction, proliferation, and plant regeneration. Plant Cell Tissue Organ Cult. 2011 Jul;106(1):1-10. doi:10.1007/s11240-010-9887-1

18. Noguchi A, Amaki W. Effects of light quality on the growth and essential oil production in Mexican mint. ActaHortic. 2016;1134:239-44. doi:10.17660/ActaHortic.2016.1134.32

19. Dou H, Niu G, Gu M, Masabni J. Effects of light quality on growth and phytonutrient accumulation of herbs under controlled environments. Hortic. 2017 Jun;3(2):36. doi:10.3390/horticulturae3020036

20. Sabzalian MR, Heydarizadeh P, Zahedi M, Boroomand A, Agharokh M, Sahba MR, et al. High performance of vegetables, flowers, and medicinal plants in a red-blue LED incubator for indoor plant production. Agron Sustain Dev. 2014 Oct;34(4):879-86. doi:10.1007/s13593-014-0209-6 
21. Li H, Tang C, Xu Z. The effects of different light qualities on rapeseed (Brassica napus L.) plantlet growth and morphogenesis in vitro. Sci Hortic. 2013 Feb;150:117-24. doi:10.1016/j.scienta.2012.10.009

22. Macedo AF, Leal-Costa MV, Tavares ES, Lage CLS, Esquibel MA. The effect of light quality on leaf production and development of in vitro-cultured plants of Alternanthera brasiliana Kuntze. Environ Exp Bot. 2011 Jan;70(1):43-50. doi:10.1016/j.envexpbot.2010.05.012

23. Lalge A, Cerny P, Trojan V, Vyhnanek T. The effects of red, blue and white light on the growth and development of Cannabis sativa L. Mendel Net; Nov; Czech Republic: Mendel University in Brno; 2017. p. 646-51.

24. Gobbi KF, Garcia R, Ventrella MC, Garcez Neto A, Rocha GC. Área foliar específica e anatomia foliar quantitativa do capim-braquiária e do amendoim-forrageiro submetidos a sombreamento. Rev Bras Zootecn. 2011;40(7):1436-44.

25. Dutra TR, Massad MD, Santana RC. Parâmetros fisiológicos de mudas de copaíba sob diferentes substratos e condições de sombreamento. Cienc Rural. 2012 Jun;42(7):1212-8. doi:10.1590/S010384782012005000048

26. Armond C, de Oliveira VC, Gonzales SDP, de Oliveira FÉR, da Silva RM, Leal TT, et al. Desenvolvimento inicial de plantas de abobrinha italiana cultivada com húmus de minhoca. Hortic Bras. 2016 Jul-Set;34(3). doi:10.1590/S0102-05362016003022

27. Darko E, Heydarizadeh P, Schoefs B, Sabzalian MR. Photosynthesis under artificial light: the shift in primary and secondary metabolism. Philos Trans R Soc Lond B Biol Sci. 2014 Mar;369(1640):19. doi:10.1098/rstb.2013.0243

28. Kochetova GV, Belyaeva OB, Gorshkova DS, Vlasova TA, Bassarskaya EM, Zhigalova TV, et al. Longterm acclimation of barley photosynthetic apparatus to narrow-band red and blue light. Photosynthetica. 2018 Sept;56(3):851-60. doi:10.1007/s11099-017-0736-x

29. Borowski E, Michałek S, Rubinowska K, Hawrylak-Nowak B, Grudziński W. The effects of light quality on photosynthetic parameters and yield of lettuce plants. Acta Sci Pol-Hortorum Cultus. 2015 Jan;14(5).

30. Kokkini S, Karousou R, Lanaras T. Essential oils of spearmint (Carvone-rich) plants from the island of Crete (Greece). Biochem Syst Ecol. 1995 Jun;23(4):425-30. doi:10.1016/0305-1978(95)00021-L

31. Peer WA, Langenheim JH. Influence of phytochrome on leaf monoterpene variation in Satureja douglasii. Biochem Syst Ecol. 1998 Jan;26(1):25-34. doi:10.1016/S0305-1978(97)00076-8 